\title{
EDITORIAL
}

\section{DERECHOS NATURALES, DERECHOS HUMANOS Y DERECHOS FUNDAMENTALES}

\author{
NATURAL RIGHTS, HUMAN RIGHTS \\ AND FUNDAMENTAL RIGHTS \\ DIREITOS NATURAIS, DIREITOS HUMANOS \\ E DIREITOS FUNDAMENTAIS
}

DOI: $10.5294 / D I K A .2016 .25 .2 .1$

La ciencia jurídica, a partir del siglo XIX y durante la primera mitad del siglo XX, estuvo dominada por el positivismo jurídico. Este es ya un lugar común. Solo a partir de la segunda mitad del siglo XX este positivismo empezó a perder su posición dominante para ceder su turno a nuevas teorias del derecho que pretendian explicar de una manera más completa y precisa el fenómeno jurídico. Entre todas las críticas al positivismo es célebre la que en los años sesenta formuló Dworkin en contra del positivismo de H. L. A. HART. La columna vertebral de esta crítica está en el hecho de que describir al derecho como un conjunto de reglas primarias y secundarias resultaba inadecuado. Además de reglas, afirma Dworkin, el derecho está compuesto por principios. Este tipo de normas jurídicas, identificadas por el profesor norteamericano en la práctica judicial de su país, se caracterizan porque su validez jurídica no depende ni de un acto institucional de poder, ni de cualquier otro hecho socialmente verificable, tal y como una práctica judicial constante entendida como vinculante, sino en virtud de su contenido. Sus mandatos son jurídicos - dice Dworkin de los principios- porque son exigencias de la justicia, la equidad o cualquier otra dimensión de la moralidad.

La crisis del positivismo significó, por tanto, la renovación de una idea de antigua y reconocida tradición: la existencia de una serie de exigencias jurídicas anteriores e independientes de cualquier hecho social, la existencia de una especie de derecho distinto y anterior al derecho positivo. Los antiguos llamaron a estas exi- 
gencias derecho natural. Así, para este iusnaturalismo, es decir, para la teoría que sostiene que además del derecho positivo existen derechos naturales, el derecho vigente en una determinada comunidad política está compuesto por exigencias positivas y naturales, las primeras provenientes de una fuente social con capacidad jurígena, las segundas anteriores e independientes de la voluntad humana. Así lo testimonia ARISTóteles, quien en la Ética Nicomaquea afirma que "la justicia política puede ser natural y legal; natural, la que tiene en todas partes la misma fuerza y no está sujeta al parecer humano; legal, la que considera las acciones en su origen indiferentes, pero que cesan de serlo una vez han sido establecidas”. ${ }^{1}$

En la filosofia contemporánea del derecho, esta idea ha vuelto a resurgir al hilo de la crítica ya reseñada, pero con un matiz y con un nombre diferente. En efecto, los filósofos del derecho contemporáneos han empezado a aceptar la idea de exigencias jurídicas anteriores a las normas positivas y que no reciben su fuerza jurídica de estas. Sin embargo, se han resistido a usar para ellas la denominación de derechos naturales. Han preferido sustraer a estas exigencias de la carga negativa que, desde la crítica que hiciera el positivismo a la teoría del derecho natural, ha lastrado el nombre "derecho natural". Para ello han creado una nueva expresión: derechos humanos o derechos del hombre. Más allá de la discusión acerca del origen histórico del concepto de derechos humanos, y de la ya larga polémica en torno a su concepción como derechos subjetivos, es cierto que existe una cierta semejanza entre aquello a lo que se referían los antiguos con la expresión "derechos naturales" y aquello a lo que se refieren los modernos con la expresión "derechos humanos". Puede ser que el concepto y, sobre todo, su fundamento no coincidan del todo, pero hay algo en ambas expresiones que resulta tener una cierta similitud. Al menos coinciden en esta anterioridad e independencia de la norma positiva, de la razón y la voluntad humana y, por tanto, se constituyen en un criterio del juicio de corrección del derecho positivo. Así las cosas, es posible establecer cierta relación de semejanza o, por lo menos, un parecido de familia entre ambas expresiones y las realidades a las cuales ellas se refieren.

Ahora bien, ni los derechos naturales, ni los derechos humanos se conforman con ser exigencias abstractas, sin ninguna vigencia real y efectiva en los ordenamientos jurídicos particulares y concretos de las comunidades politicas existentes. Estas exigencias reclaman, por su misma naturaleza, su positivización, es decir, la inclusión en los diferentes y disimiles ordenamientos jurídicos vigentes, no porque requieran de ello para su existencia (los derechos naturales y los derechos humanos existen con independencia de su positivización), sino porque si el ordenamiento jurídico vigente ha de tener cierta unidad y completitud debe reconocer y concretar estas exigencias, para saber cómo y bajo qué condiciones pueden ser realizados en cada situación particular y concreta, y cómo pueden ser mejor garantizados y protegidos. La concreción de estas exigencias es una necesidad intrínseca al concepto de derecho natural / derecho humano porque él mismo exige su realización plena y efectiva, y ello solo puede hacerse a través del derecho positivo, que delimita el derecho para hacerlo exigible de una mejor manera en las circunstancias concretas.

1 Aristóteles, Ética Nicomaquea, V, 7, a20. 
Esto no quiere decir que sin la mediación del derecho positivo no sean exigibles los derechos naturales, pero sí es verdad que sin ella tal cosa se hace más difícil.

La positivización de los derechos humanos da lugar al concepto de derechos fundamentales. Así las cosas, estos son derechos positivos que reconocen exigencias de derechos humanos incluidas en el ordenamiento jurídico-positivo de una comunidad politica determinada, y ello por su expresa disposición o querer. Ahora bien, no todos los derechos humanos / naturales deben estar expresamente reconocidos por el derecho positivo, pues hemos dicho que su existencia no depende de este reconocimiento, pero sí es verdad que hay ciertos derechos humanos / naturales que son tan importantes para toda comunidad politica y para su viabilidad y persistencia, que dificilmente pueden ser excluidos del catálogo de los derechos fundamentales. Otros, en cambio, dependen de ciertas contingencias. De esta manera, se establece una especie de relación entre las nociones de derechos naturales, derechos humanos y derechos fundamentales que nos permite concluir que, aunque se puedan establecer ciertas diferencias entre ellas, comparten ciertas notas características que han permitido a muchos, y nos permiten a nosotros hablar ahora de una especie de renacimiento del concepto de derecho natural.

Solo esta constatación es suficiente para que filósofos del derecho y académicos en general vuelvan nuevamente su mirada a esta noción y se renueve el interés por dilucidar su papel en la comprensión del fenómeno jurídico y su relación con los conceptos de derechos humanos y derechos fundamentales. En este orden de ideas se puede preguntar: ¿tiene algo que decir la teoría clásica del derecho natural a los filósofos contemporáneos del derecho? ¿Tienen sus reflexiones acerca del derecho natural algún interés para la filosofia del derecho contemporánea? En la tarea de comprender mejor los derechos humanos y los derechos fundamentales, ¿tiene algo qué decir o aportar esa ya antigua y olvidada teoría del derecho natural clásico? Estas preguntas deben ser consideradas por aquellos que se dediquen, en su tarea investigativa, a la comprensión de la naturaleza y modo de ser de ese tipo de exigencias anteriores e independientes de los derechos positivos a las que llamamos derechos humanos, y cuya positivización da lugar a los derechos fundamentales.

JOSÉ JULIÁN SUÁREZ-RODRÍGUEZ

Editor 